\title{
GUIDELINES FOR ASSESSMENT AND INITIATION OF THERAPEUTIC HYPOTHERMIA (COOLING) TREATMENT FOR MODERATE OR SEVERE HYPOXIC ISCHAEMIC ENCEPHALOPATHY
}

Surantha Perera ${ }^{1}$, Amit Gupta ${ }^{2}$

\section{AIMS OF THE GUIDELINE}

- To ensure that babies with suspected HIE are appropriately assessed to see whether therapeutic hypothermia (cooling) is appropriate.

- To ensure that cooling is initiated in a safe and timely manner.

- To outline the care pathway for ongoing cooling treatment.

\section{INTRODUCTION}

Neonatal encephalopathy has an incidence of approximately $3 / 1000$ births, with hypoxic ischaemic encephalopathy occurring in approximately 1.3-1.7/10001 and more specifically, moderate-severe HIE occurring in approximately 1.0-1.5/1000 live births in the $\mathrm{UK}^{1,2}$. The risk of death or severe handicap in survivors of moderate or severe HIE is approximately 25 and $75 \%$ respectively ${ }^{3}$, and children without cerebral palsy are at increased long-term risk of cognitive and behavioural problems as well as motor deficits ${ }^{4}$.

A recent Cochrane Review that included 11 trials on therapeutic hypothermia such as the UK total body cooling trial (TOBY) and US National Institute of Child Health and Human Development (NICHD) trial, confirmed that therapeutic hypothermia reduces death and disability at 18 months of age and improves neurodevelopmental outcomes in survivors with a number needed to treat of 7-11, depending on the outcome measured ${ }^{5}$. Other meta-analysis have confirmed this finding and showed that the number needed to treat for survival with normal neurological function at 18 months is 7 (95\% CI 5-11) ${ }^{6}$ and 8 (95\% CI 5- 17) ${ }^{7}$, respectively. Recently published longer-term data at the age of 6-7 years by the TOBY and NICHD groups showed a benefit of therapeutic hypothermia for reduction of death and improvement of neurodevelopmental outcome up to school age ${ }^{8,9}$. Clinically significant adverse events attributed to cooling are uncommon and the benefits of therapeutic hypothermia outweigh the possible short-term adverse effects 5 .

Therapeutic hypothermia is now standard of care in selected neonates with HIE and is supported by NICE and BAPM ${ }^{10,11}$.

\section{CRITERIA FOR COOLING}

- Cooling should be considered in all infants that meet criteria A and B (Table1).

- Criteria B can be assessed and recorded shortly after delivery. However, the baby should be reassessed when the patient is more than 30 minutes old to allow time for spontaneous recovery post resuscitation.

- Where an infant meets criteria A; but it is not possible to assess criteria B (e.g. paralyzing agents have been used prior to clinical neurological assessment), cooling should be commenced and the aEEG should be used to assess ongoing need for cooling.

Initiation of cooling should not be delayed if aEEG is not readily available. 


\begin{tabular}{|l|l|}
\hline \multicolumn{1}{|c|}{ CRITERIA - A } & \multicolumn{1}{c|}{ CRITERIA - B } \\
\hline $\begin{array}{l}\text { Infants } \geq \mathbf{3 6} \text { completed weeks gestation } \\
\text { admitted to NICU with } \\
\text { at least one of the following: }\end{array}$ & $\begin{array}{l}\text { Seizures (clinical or subclinical*) or } \\
\text { moderate to severe encephalopathy, } \\
\text { consisting of: }\end{array}$ \\
$\begin{array}{l}\text { Apgar score of } \leq 5 \text { at } 10 \text { minutes } \\
\text { after birth }\end{array}$ & $\begin{array}{l}\text { Altered state of consciousness } \\
\text { (reduced or absent response to } \\
\text { stimulation) AND }\end{array}$ \\
$\begin{array}{l}\text { Continued need for resuscitation, } \\
\text { including endotracheal or mask } \\
\text { ventilation, at } 10 \text { minutes after birth }\end{array}$ & $\begin{array}{l}\text { Abnormal tone (focal or general } \\
\text { hypotonia, or flaccid) AND }\end{array}$ \\
$\begin{array}{l}\text { Acidosis within } 60 \text { minutes of } \\
\text { birth (defined as any occurrence of } \\
\text { umbilical cord, arterial or } \\
\text { capillary pH }<7 .\end{array}$ & $\begin{array}{l}\text { Abnormal primitive reflexes } \\
\text { (weak or absent suck or Moro } \\
\text { response) }\end{array}$ \\
$\begin{array}{l}\text { Base Deficit } \geq 16 \text { mmol/L in } \\
\text { umbilical cord or any blood } \\
\text { sample (arterial, venous or } \\
\text { capillary) within } 60 \text { minutes of } \\
\text { birth }\end{array}$ & $\begin{array}{l}\text { * Subclinical seizures are those which are } \\
\text { detected on amplitude integrated EEG } \\
\text { (aEEG) but there are no clinical signs } \\
\text { apparent. }\end{array}$ \\
\hline
\end{tabular}

\section{COOLING OUTSIDE TRIAL GUIDELINES}

Evidence for cooling outside the above guidelines is weak or unavailable. However, there are circumstances where there may be theoretical benefits for cooling in certain other patients ${ }^{12-14}$. Cooling in these circumstances should only be instigated following discussion with the cooling centre.

\section{Examples would include:}

- Infants who fulfil criteria $\mathrm{A}+\mathrm{B}$ but are between 6-12 hours old.

- Preterm infants, 33+weeks or more, who have suffered an acute asphyxia event and fulfil criteria $\mathrm{A}+\mathrm{B}$ above.

- Acute postnatal collapse with a neurological examination consistent with a diagnosis of acute encephalopathy.

- Early prolonged or recurrent seizures (within 12 hours of birth).

- Infants who fulfil criteria A but only partially fulfil criteria B.

\section{CONTRAINDICATIONS TO COOLING}

There are no absolute contraindications to cooling infants who meet the criteria above except where there are other life-threatening congenital abnormalities present. Relative contra-indications include:

- Suspected significant haemorrhage or thrombosis (NB although hypothermia prolongs bleeding time, trials did not 
demonstrate differences in complications related to abnormal clotting).

- Surgical conditions likely to be associated with significant blood loss.

- Severe PPHN - Cooling may produce adverse respiratory or cardiovascular effects. However, trials found no difference in the prevalence of PPHN between cooled patients and control groups.

\section{AMPLITUDE INTEGRATED EEG (aEEG) ASSESSMENT}

The aEEG (also known as Cerebral Function Monitor-CFM) is a single or dual channel time compressed and filtered EEG providing information on overall electrical activity in the brain.

- The amplitude integrated EEG (aEEG or CFM) must be recorded in all infants treated with cooling but cooling should not be delayed until the aEEG is initiated.

- A normal aEEG record indicates a high probability of normal outcome, and clinicians may consider that treatment with cooling is not required.

- Rewarming following active cooling may be considered if the clinical examination is normal and the CFM normalizes within the first 6 hours. However, ongoing neurological examination and CFM recording should occur during rewarming and if any signs of deterioration occur the patient should be re-cooled for the full 72 hours.

Apparent improvement of the aEEG AFTER 6 hours of age is NOT an indication for discontinuing cooling.
- A copy of the initial CFM traces should be sent with the baby to the cooling centre.

- IV anticonvulsant therapy may cause transient suppression of EEG activity. Ideally the aEEG should be performed before administering anticonvulsant therapy.

\section{VENTILATION}

- Most infants treated with cooling will initially require mechanical ventilation as a consequence of their encephalopathy/ anticonvulsant medication.

- Ventilatory care should be managed according to local protocol

- Bolus doses of paralysis should be used if required rather than infusions to prevent drug accumulation.

- Blood gases will guide ventilatory requirements; particular care should be taken to ensure normocapnia. The infant's temperature should be inputted into the blood gas machine so that the appropriate adjustment is performed.

- Ventilator gases should be warmed and humidified in the normal way.

- More frequent suctioning may be necessary as secretions tend to be more viscous when cold. Vary positioning 6 hourly, Chest physio as indicated.

\section{CARDIOVASCULAR SUPPORT}

- Most infants with a rectal temperature of 33$34^{\circ} \mathrm{C}$ will have a heart rate around $100 \mathrm{bpm}$ and a mean blood pressure greater than 40 mmHg. 
- Treatment with volume replacement and inotropes should be considered if the mean arterial blood pressure is less than $40 \mathrm{mmHg}$.

\section{ANALGESIC AND SEDATIVE THERAPY}

- Stress may have adverse effects in asphyxiated infants and may influence the therapeutic effect of hypothermia. Signs of distress include tachycardia, facial grimacing and irritability. A heart rate consistently above $110 \mathrm{bpm}$ in cooled infants suggests that the infant is distressed (exclude hypotension/ hypovolaemia and other causes of pain).

- Ventilated infants should be sedated with intravenous morphine as per local unit guidelines.

- Non-ventilated infants will also require morphine therapy, commenced at $10 \mathrm{mcg} / \mathrm{kg} /$ $\mathrm{hr}$. Respiratory function must be monitored in these infants. There should be a low threshold for commencing ventilation, if required, in order to give adequate sedation/pain relief.

\section{FLUID \& ELECTROLYTE MANAGEMENT}

- Renal function is commonly impaired following severe perinatal asphyxia and fluids should be restricted.

\section{COAGULATION}

- Send platelet count and clotting at the start of cooling. If there are clinical signs of increased bleeding tendency, treat babies with FFP without waiting for lab results.

\section{SEPSIS}

- Antibiotic therapy may be given if clinically indicated. Gentamycin and other aminoglycosides should be avoided as there is a higher risk of toxicity

\section{SEIZURES}

- The management of seizures should be as usual

- In general, symptomatic seizures or frequent subclinical $(>3 / \mathrm{hr})$ seizures seen on aEEG/ CFM should be treated with anticonvulsants.

- Cooling may affect the metabolism of several drugs, including anticonvulsants and sedatives, and toxic drug levels may occur even with normal doses.

\section{REFERENCES}

01. Kurinczuk JJ, White-Koning M,Badawi N.Epidemiology of neonatal encephalopathy and hypoxic-ischaemic encephalopathy. Early Hum Dev 2010; 86(6):329-38

02. Azzopardi D, Strohm B, Linsell L,Hobson A, Juszczak E, Kurinczuk JJ, Brocklehurst P, Edwards AD. Implementation and conduct of therapeutic hypothermia for perinatalasphyxia encephalopathy in the UK - analysis of national data. PLoD One 2012;7(6): e38504

03. Marlow N, Rose AS, Rands CE,Draper ES.Neuropsychological and educational problems at school age associated with neonatal encephalopathy. Arch Dis Child Fetal Neonatal Ed2005;90 (5):F380-F387.

04. De Vries LS, Jogmans MJ. Long-term outcome after neonatal hypoxic-ischaemic encephalopathy. Arch Dis Child Fetal Neonatal Ed 2010; 95:F220-F224 
05. Jacobs SE, Berg M, Hunt R, TarnowMordi WO, Inder TE, Davis PG. Cooling for newborns with hypoxic ischaemic encephalopathy (Review). Cochrane Database of Systemic Reviews 2013

06. Tagin MA, Woolcott CG, Vincer MJ, Whyte RK, Stinson DA. Hypothermia for Neonatal Hypoxic Ischemic Encephalopathy. Arch Pediatr Adolesc Med. 2012; 166(6):558-566

07. Edwards AD, Brocklehurst P, Gunn AJ, Halliday H Juszczak E, Levene M, Strohm B, Thoresen M, Withelaw A, Azzopardi D. Neurological outcomes at 18 months of age after moderate hypothermia for perinatal hypoxic- ischaemic encephalopathy: synthesis and meta-analysis of trial data. BMJ 2010; 340:c363

08. Azzopardi D et al. Effect of Hypothermia for Perinatal Asphyxia on Childhood Outcomes. N Engl J Med 2014;371:140-9

09. Shankaran S et al. Childhood Outcomes afterHypothermia for Neonatal Encephalopathy. N Engl J Med. 2012;366(22):2085-2092

10. NICE Interventional Procedure Guidance 347. Therapeutic Hypothermia with intracorporeal temperature monitoring for hypoxic Perinatal brain injury. May 2010

11. British Association of Perinatal Medicine. Position Statement on Therapeutic Cooling for Neonatal Encephalopathy. July 2010

12. Hall NJ, Eaton S, Peters MJ, Hiorns MP, Alexander N, Azzopardi DV, Pierro A. Mild controlled hypothermia in preterm neonates with advanced necrotizing enterocolitis. Pediatrics 2010; 125(2): e300-8.
13. Smit E, LiuX, Cowan F, Thoresen M. Cooling neonates who do not fulfil the standard cooling criteria - short and longterm outcomes. Acta Paediatr 2015; 104(2):138-45

14. Austin A, Shanmugalingam S, Clarke P. To cool or not to cool? Hypothermia treatment outside trial criteria. Arch Dis Child Fetal Neonatal Ed. 2013; 98(5): F451-3.

(Adapted from John Radcliffe University Hospital, Oxford, NICU Guidelines)

\section{${ }^{1}$ Consultant Paediatrician \\ Castle Street Hospital for Women, Colombo, Sri Lanka}

${ }^{2}$ Clinical Lead and Consultant Neonatologist, John Radcliffe University Hospital Oxford, UK 